Ермағамбет Болат Толеуханұлы д.Х.н., профессор, директор E-mail: coaltech@bk.ru ORCID ID 0000-0003-1556-9526

Казанкапова Майра Куттыбаевна $\mathrm{PhD}$, ведущий научный сотрудник E-mail: maira_1986@mail.ru ORCID ID 0000-0001-9016-3062

TOO «Институт химии угля и технологии»

Женисова Акмарал Камзиевна, магистрант

Казахский университет технологии и бизнеса младший научный сотрудник ТОО «Институт химии угля и технологии» E-mail: ms.tanabaeva95@mail.ru ORCID ID 0000-0001-7529-0223 г.Астана, Республика Казахстан

\title{
ПОЛУЧЕНИЕ АКТИВИРОВАННОГО АДСОРБЕНТА НА ОСНОВЕ УГЛЯ МЕСТОРОЖДЕНИЯ «ШОПТЫКОЛЬ» МАЙКУБЕНСКОГО БАССЕЙНА
}

Yermagambet Bolat Toleukhanuly, Doctor of Chemistry, Professor, Director E-mail: coaltech@bk.ru ORCID ID 0000-0003-1556-9526 Kazankapova Maira Kuttybayevna, PhD, Leading Researcher E-mail: maira_1986@mail.ru ORCID ID 0000-0001-9016-3062 Institute of Coal Chemistry and Technology Zhenisova Akmaral Kamzievna, Master's Degree student Kazakh University of Technology and Business Junior Researcher of LLP "Institute of Coal Chemistry and Technology" E-mail: ms.tanabaeva95@mail.ru ORCID ID 0000-0001-7529-0223 Astana, the Republic of Kazakhstan

\section{THE RECEIVING AN ACTIVATED ADSORBENT ON THE BASIS OF COAL THE «SHOPTYKOL» FIELD OF THE MAYKUBEN BASIN}

\begin{abstract}
Annotation. The article shows experiments on heat treatment of coal at the Shoptykol deposit of the Maikuben basin by means of its carbonization and activation. First, carbonization of coal was carried out in an inert atmosphere of argon in the temperature range of $25-700^{\circ} \mathrm{C}$ and then the activation of coal with water vapor at a temperature of 700-800 ${ }^{\circ} \mathrm{C}$. With the help of energy dispersive X-ray spectroscopy on an SEM instrument (Quanta 3D 200i) with an attachment for energy dispersive analysis from EDAX, its chemical composition and surface morphology of the samples were determined. The BET method is used to determine the adsorption characteristics of the samples. It was found that the specific surface area and specific pore volume significantly increased as a result of high-temperature coal. Tests on approbation of the obtained activated carbon as an adsorbent for the purification of gas and water.
\end{abstract}

Keywords: coal, adsorbent, "Shoptykol", carbonization, activation, cleaning

Аннотация. В статье проведень эксперименты по термической обработке угля месторождении «Шоптыколь» Майкубенского бассейна путем его карбонизачии и активации. Сначала проводили карбонизаџию угля в инертной среде аргона в интервале температур $25-700{ }^{\circ} \mathrm{C}$ и затем активацию угля водяным паром при температуре 700-800 ${ }^{\circ} \mathrm{C}$. C помощью энергодисперсионной рентгеновской спектроскопии на приборе SEM (Quanta 3D 200i) c приставкой для энергодисперсионного анализа от ЕDAX определен его химический состав и морфология поверхности образиов. Методом БЭТ определены адсорбционные характеристики образиов. При этом установлено, что удельная поверхность и удельный объем пор существенно повышаются в результате высокотемпературной угля. 
Проведены испытания по апробачии полученного активированного угля

в качестве адсорбента для очистки газа и воды.

Ключевые слова: уголь, адсорбент, «Шоптыколь», карбонизащия, активачия, очистка

Последние десятилетия ознаменовались всплеском научной активности по разработке и изучению углеродных материалов. Это нашло отражение в целенаправленном синтезе аллотропных форм углерода (карбинов, фуллеренов, нанотрубок, циркуленов и др.), а также в создании широкого спектра пористых материалов в ряду смешанных (переходных) форм углерода, представляющих практический интерес в качестве адсорбентов, катализаторов и носителей для катализаторов.

Сохранение водных ресурсов планеты считается одной из основных задач развития современной науки, а очистка питьевых и промышленных сточных вод важным этапом ее решения. Существует различные решения методы очистки воды, но наиболее простым и широко известным является адсорбционный метод, основанный на использование твердых сорбентов. При этом следует отметить, что уровень производства отечественных марок углеродных материалов, пригодных в качестве адсорбентов, остается не высоким.

Существует различные схемы получения углеродных материалов, которые включают подготовку и модифицирование исходного угля, карбонизацию и последующую активацию газом или химическим реагентом.

Майкубенский буроугольный бассейн, включающий Шоптыкольское, Сарыкольское и Талдыкольское месторождения известен с начала XIX века. С 1941 г. на Шоптыкольском месторождении ведётся разработка угля небольшим карьером для местных нужд, а с 1987 г. крупным разрезом Майкубенским проектной мощностью 20 млн.т/год.

Угли бассейна гумусовые, бурые высокой степени углефикации (Б3), среднезольные (25-28\%). Зола тугоплавкая, с высоким содержанием $\mathrm{Al}_{2} \mathrm{O}_{3}$ (до $30 \%$ ), угли малосернистые $(0,5-1,0 \%)$ и многофосфористые $(0,1 \%)$. Теплота сгорания на горючую массу 7-7,5 тыс.ккал/кг. Выход смол 4-7 \%, редко $10 \%$, гуминовых кислот 5 \% на сухой уголь для Шоптыкольской свиты и битумов около 2,5 \%. Общие запасы углей бассейна оцениваются в 5,3 млрд.т, в том числе пригодные для открытой отработки при вскрыше до $10 \mathrm{~m}^{3} / \mathrm{T}$ составляют 1,8 млрд.т [1].

В связи со стремительным развитием «зеленой энергетики», добыча твердых топлив в мире, как энергетическое сырье сокращается. Это обуславливает поиск высокоэффективных технологий комплексной переработки горючих ископаемых в продукты с высокой добавочной стоимостью высокого передела, что является актуальной задачей науки и промышленности. Так, стоимость углеродных нанотрубок на мировом рынке колеблется от 30 до 100 долл. за 1 кг., стоимость наносорбентов в 450 раз превышает стоимость сырья при огромном объеме рынка сбыта, а суммарное мировое производство пористых углеродных материалов в настоящее время составляет около 1 млн. т. в год [2].

Цель данной работы - получения пористо-углеродных материалов (адсорбентов) на основе угля месторождении «Шоптыколь» Майкубенского бассейна для очистки газовой фазы от кислых компонентов и сточных вод.

Образцы активированного угля были получены в ТОО «Институт химии угля и технологии» (г. Астана) карбонизацией (при 700-750 ${ }^{\circ} \mathrm{C}$ в среде аргона) и активацией (при $850-900{ }^{\circ} \mathrm{C}$ водяным паром) угля в соответствии с методикой, описанной в [3]. Технические характеристики исходного и активированного угля составляет (мас. \%): $A^{d}-22,06 ; W^{r}-8.61$; $V^{d}-37,13$ и $A^{d}-15.61 ; W^{r}-1.72 ; V^{d}-10.86$. 
Химический анализ исходного и активированного угля проводили методом энергодисперсионной рентгеновской спектроскопии на приборе SEM (Quanta 3D 200i) с приставкой для энергодисперсионного анализа от EDAX в Национальной нанотехнологической лаборатории открытого типа (КазНУ имени аль-Фараби, г. Алматы). Энергия возбуждающего пучка электронов при анализе составила 15 кэВ. Результаты элементного анализа представлены в таблице 1.

Влажность, зольность и летучесть сланцев определяли на термогравиметрическом анализаторе «Thermoster Eltra» (согласно ASTM D7582-12 «Standard Test Methods for Proximate Analysis of Coal and Coke by Macro Thermogravimetric Analysis»). Насыпную плотность, рН водной вытяжки, адсорбционную активность по метилоранжу определяли в соответствии с методиками $[4,5]$.

Для идентификации фазового состава активированного угля использовали рентгеновскую дифракцию. Рентгенофазовый анализ проводили на установке ДРОН-2. Условия съёмки: $\mathrm{FeK} \alpha-$ излучение, $U=28$ кВ $J=28 \mathrm{~mA}$. В результате анализа установлено, что активированный уголь практически рентгеноаморфен, наблюдаются слабые рефлексы $\mathrm{SiO}_{2}, \mathrm{Fe}_{2} \mathrm{O}_{3}$ и $\mathrm{K}_{2} \mathrm{O}$.

Таблииа 1 -Химический состав активированного угля Майкубенского бассейна

\begin{tabular}{|c|c|c|}
\hline Элемент & Исходный, \% & Активированный. \% \\
\hline $\mathrm{C}$ & 80,88 & 93,29 \\
\hline $\mathrm{O}$ & 17,93 & 6,25 \\
\hline $\mathrm{Si}$ & 1,19 & 1,02 \\
\hline
\end{tabular}

Адсорбционные характеристики образцов (удельная площадь поверхности, удельный объем пор по предельному заполнению) изучали методом Брунауэра-ЭмметаТеллера (БЭТ). Измерения проводили на приборе КАТАКОН Sorbtometer М.

Результаты проведенного исследования по определению основных физикохимических характеристик исходного угля и активированного адсорбента приведены в таблице 2.

Таблица 2 - Физико-химических характеристики исходного и активированного угля месторождения «Шоптыколь» Майкубенского бассейна

\begin{tabular}{|c|c|c|c|c|c|c|}
\hline Наименование & $\begin{array}{c}\text { Суммар- } \\
\text { ный } \\
\text { объем } \\
\text { пор по } \\
\text { воде, } \\
\mathrm{cm}^{3} / \Gamma \\
\end{array}$ & 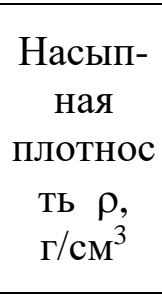 & $\begin{array}{c}\mathrm{pH} \\
\text { водной } \\
\text { вытяжки }\end{array}$ & $\begin{array}{c}\text { Адсорбцион } \\
\text { ная } \\
\text { активность } \\
\text { по } \\
\text { метилоранж } \\
\text { у, мг/г } \\
\end{array}$ & $\begin{array}{c}\text { Удельная } \\
\text { поверхност } \\
\text { ь, м²/г } \\
\text { (одноточеч } \\
\text { ный метод } \\
\text { БЭТ) } \\
\end{array}$ & $\begin{array}{c}\text { Удельный } \\
\text { объём пор, } \\
\text { см}^{3} / \Gamma \text { (по } \\
\text { предельному } \\
\text { заполнению) }\end{array}$ \\
\hline $\begin{array}{c}\text { Исходный } \\
\text { уголь } \\
\text { месторождени } \\
\text { я } \\
\text { «Шоптыколь» }\end{array}$ & 0,20 & 0,602 & 7,28 & 5,0 & 1,462 & 0,001 \\
\hline $\begin{array}{c}\text { Активированн } \\
\text { ый адсорбент } \\
\text { «Шоптыколь» }\end{array}$ & 0,57 & 0,502 & 6,60 & 51,0 & 100,581 & 0,043 \\
\hline
\end{tabular}


Результаты анализа микроснимков показывают, что после термической активации угля поверхностная структура изменяется и становится более развитой, с меньшими размерами частиц (от 40 нм до 60). В некоторых местах наблюдается поверхность скола пластинчато-ступенчатой формы. Как видно из полученных данных, в активированых адсорбентах по сравнению с исходным углем (таблица 2) удельная поверхность и удельный объем пор существенно повышается.
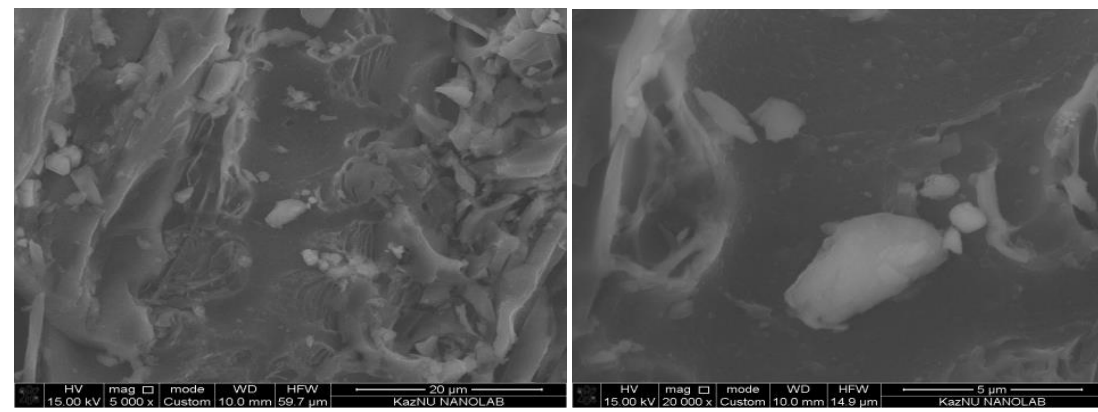

a)

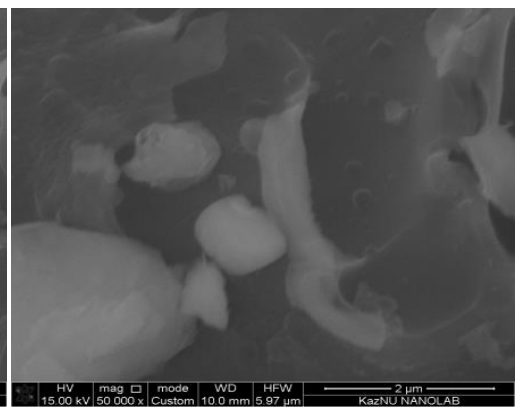

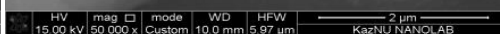
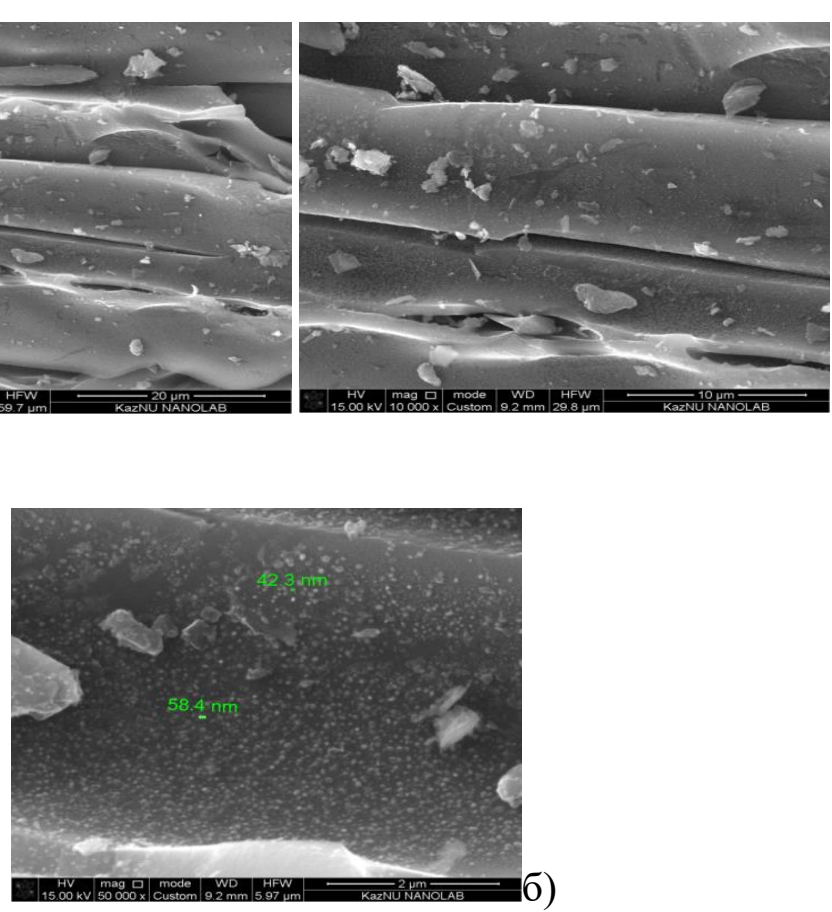

Рисунок 1 - Электронные микроскопические снимки исходного (а) и активированного адсорбента (b) на основе угля месторождения «Шоптыколь» (бассейн «Майкубен»)

Полученные образцы активированного угля были апробированы в качестве адсорбента для очистки газов (состава: $\mathrm{CO}_{2}, \mathrm{~N}_{2}, \mathrm{CH}_{4}, \mathrm{CO}, \mathrm{H}_{2} \mathrm{~S}$ ). Результаты проведенного элементного анализа до и после очистки газов с определением степени очистки представлены в таблице 3. 
Таблица 3 - Результаты элементного анализа газов до и после очистки газов адсорбентом

\begin{tabular}{|c|c|c|c|c|c|c|c|c|c|c|}
\hline \multirow{2}{*}{ Наименование } & \multicolumn{5}{|c|}{ Концентрация газов \% } & \multicolumn{5}{c|}{ Степень очистки\% } \\
\cline { 2 - 11 } & $\mathrm{CO}_{2}$ & $\mathrm{~N}_{2}$ & $\mathrm{CH}_{4}$ & $\mathrm{CO}$ & $\mathrm{H}_{2} \mathrm{~S}$ & $\mathrm{CO}_{2}$ & $\mathrm{~N}_{2}$ & $\mathrm{CH}_{4}$ & $\mathrm{CO}$ & $\mathrm{H}_{2} \mathrm{~S}$ \\
\hline Исходный газ & 16,97 & 21,20 & 4,45 & 5,71 & 0,398 & - & - & - & - & - \\
\hline $\begin{array}{c}\text { Активированн } \\
\text { ый адсорбент } \\
\text { "Шоптыколь” }\end{array}$ & 3,57 & 22,21 & 4,50 & 3,57 & 0,009 & 78,99 & - & - & 37,59 & 97,70 \\
\hline
\end{tabular}

Анализ полученных результатов показывает, адсорбент на основе угля месторождения «Шоптыколь» можно применить в качестве фильтра при очистке $\mathrm{CO}_{2}$ $(78,99 \%)$ и $\mathrm{H}_{2} \mathrm{~S}(97,70 \%)$.

Активированный адсорбент также был апробирован для очистки нефти и железа. Для проведения исследовании по очистке нефти, в 100 мл колбу с водой добавляется 10 г адсорбента и 1 мл нефти, затем помещается в шейкер на 16 часов при температуре $25{ }^{0} \mathrm{C}$, при скорости вращения 200 об/мин. Затем проба фильтруется ватой и смешивается с 10 мл гексана для экстракции органическую часть. Остаточную концентрацию после очистки определяли в спектрофотометре PD-303 для расчета степени очистки. Степень очистки адсорбента от нефти составил - 94,18\%.

Для апробации адсорбента для очистки воды от железа, готовили $10 \%$ раствор роданида калия. Для получения градуировочного графика, готовим раствор А, для этого 0.08634 г $\mathrm{NH}_{4} \mathrm{Fe}\left(\mathrm{SO}_{4}\right) * 12 \mathrm{H}_{2} \mathrm{O}$ растворяют в дистиллированной воде, подкисляют соляной кислотой (до растворения мути), 1 мл такого раствора содержит 0,1 мг железа. Разбавлением основного раствора в 10 раз получаем раствор В, в 1 мл которого содержится 0,01 мг железа. Берем раствор А раствор и в 6 мерных колб по 50 мл вводим по 0,5; $1 ; 2 ; . .6$; рабочего раствора, затем доводим до метки водой.

Для приготовления раствора на анализ воды берем 500 мл колбу добавляем 15 мл А раствора, 10 мл соляной кислоты и 50 мл роданид калия, затем в колбу наливаем 100 мл А раствора и 0,5 г адсорбента ставим в шейкер на 5 часов. Затем фильтруем и определяем степень очистки в спектофотометре. Степень очистки адсорбента от железа составил $99,38 \%$.

Таким образом, в результате высокотемпературных процессов карбонизации (в инертной среде) и активации (водяным паром) угля месторождения «Шоптыколь» Майкубенского бассейна получен пористый углеродный материал, c удельной поверхностью $100,581 \mathrm{~m}^{2} / \Gamma$ и удельным объемом пор $0,043 \mathrm{~cm}^{3} / \Gamma$, обладающий более развитой и упорядоченной поверхностной структурой, а также более высокими адсорбционными свойствами. В связи с этим активированный уголь можно рассматривать перспективным, в частности, в качестве адсорбента для очистки жидких сред (от нефтепродуктов, тяжелых металлов (Fе и др.) и т.д.) и газов $\mathrm{CO}_{2}\left(78,99 \%\right.$ ) и $\mathrm{H}_{2} \mathrm{~S}(97,70 \%)$.

Работа выполнена в рамках научно-технической программы № BR05236359 по теме: "Научно-технологическое обеспечение переработки углей и производство продуктов углехимии высокого передела» и по проекту № АР05130707 «Разработка технологии и создание производства углеродных нанокомпозитных материалов на основе 
минерального отечественного сырья для очистки газовой фазы и сточных вод» финансируемой Комитетом науки МОН РК.

\section{ЛИТЕРАТУРА}

1. Азизов Т.М., Власов В.И. Бассейны и месторождения углей и горючих сланцев Казахстана // Справочник. - Алматы. - 1997. - С. 91-101.

2. Б.Т. Ермагамбет, Б. К. Касенов, Н. У. Нургалиев, М. А. Набиев, Ж.М. Касенова, М.К. Казанкапова, А.М. Зикирина. Электрофизические свойства и теплоемкость сланца Кендырлыкского месторождения // Химия твердого топлива, 2018, №1, с.68-72

3. Sanchez, A.R., Elguezabal A.A., Saenz L.T., $\mathrm{CO}_{2}$ activation of char from wood waste // Carbon. 2001. V. 39. P. 1367-1377.

4. ГОСТ 4453-74 Уголь активный осветляющий древесный порошкообразный. Технические условия

5. Кабулов А.Т., Нечипуренко С.В., Ефремов С.А. // Труды Кольского научного центра РАН. 2015. № 5(31). C. 527 